\title{
HOMENAGEM AO PROFESSOR ROGERIO LUIZ QUINTINO DE OLIVEIRA JÚNIOR
}

$(14 / 05 / 1981-17 / 08 / 2021)$

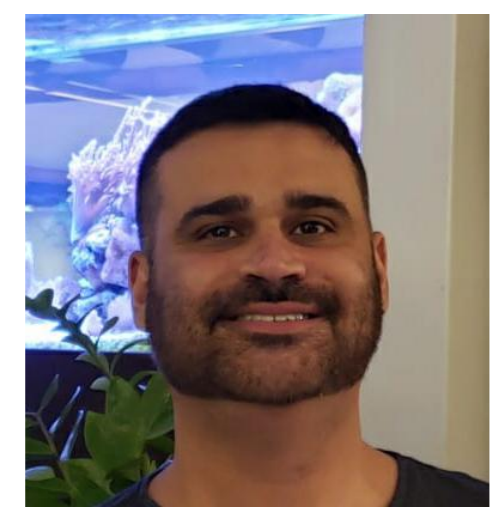

Rogerio (Fev/2021)

O Cadernos do IME - Série Matemática, dedica a sua edição n.17 (2021) ao professor Rogerio Luiz Quintino de Oliveira Junior que, infelizmente, faleceu no dia 17/08/2021. O professor Rogerio fez toda sua formação acadêmica na Universidade Federal do Rio de Janeiro (UFRJ) - Bacharelado, Mestrado e Doutorado em Matemática - tendo sido orientado pela professora Ângela Biazutti no Mestrado e pelo professor Flávio Dickstein no Doutorado. Desde 2005 atuou como professor em várias instituições e em 2012 foi aprovado em concurso para professor adjunto no Departamento de Análise Matemática do Instituto de Matemática e Estatística da Universidade do Estado do Rio de Janeiro (IME-UERJ). Rogerio era bastante ativo, exercendo cargos de administração além de sempre se dedicar ao ensino e pesquisa. Ele foi supervisor de monitores de Equações Diferenciais Ordinárias (EDO), ocupou o cargo de Coordenador do PROFMAT da UERJ, pólo Maracanã, de 2019 até 2021, e participou da Especialização em Aprendizagem em Matemática. Neste último ano, 2021, se juntou à nossa equipe de editores ocupando o cargo de Editor de Seção, sendo responsável pela seção "Cadernos de Notas". Sempre se mostrou motivado e preocupado em aprender sobre o funcionamento da revista. Rogerio era muito querido por todos ao seu redor. Tinha um ótimo relacionamento com os alunos, orientou 6 dissertações de mestrado e 4 monografias de especialização. 
Nesta dedicatória convidamos sua ex-orientadora de Mestrado, a professora Ângela Biazutti (UFRJ), sua companheira na coordenação no PROFMAT, a professora Rosa García (FFP-UERJ) e um dos seus últimos orientandos no PROFMAT, Daniel Lima, para escreverem mensagens em sua homenagem. As cartas estão anexadas a seguir:

\section{Depoimento da professora Rosa García (FFP- UERJ)}

Rogerio tinha três grandes paixões: a Matemática, a Música e os seus animais de estimação. Mostrava um grande amor pela UERJ, e nessa época de pandemia do Corona vírus, sentia muita falta dos colegas, das amigas do bandejão e de seus alunos.

"Visitando minha amada UERJ. Que saudades dessa universidade e de trabalhar lá. Que saudades do contato olho a olho com meus alunos e orientandos. Que saudades dos meus colegas de trabalho. Que saudade!"

Rogerio (12/03/21) - Mensagem no Facebook

Rogerio descobriu a vocação para o ensino e fez disso um ofício desde os 12 anos de idade quando começou a trabalhar como explicador e, aos 15 anos, já tinha relativa independência econômica.

Em meados do ano 2018, conheci o professor Rogerio no IMPA, em uma das primeiras reuniões que tivemos como coordenadores dos polos do Maracanã e de São Gonçalo do PROFMAT da UERJ. Nos dois estávamos tensos, inseguros e cheios de dúvidas em relação às normas do PROFMAT e suas plataformas como a Sucupira, a Intranet etc. Coube à professora Patrícia Nunes (IME-UERJ) ser paciente conosco, nos tranquilizando sobre as normas e as plataformas em vigor.

Rogerio sempre se mostrava atencioso e calmo, não reclamando do trabalho excessivo, nem mesmo quando tínhamos que responder as diversas enquetes do PROFMAT, durante o longo período de isolamento social. Nessa época, ficamos mais próximos um do outro, permitindo com isso a troca de saberes. Ele comentava que estava preparando o curso de verão do PROFMAT de 2022 e também se encontrava feliz por estar finalizando uma orientação do mestrado profissionalizante. 


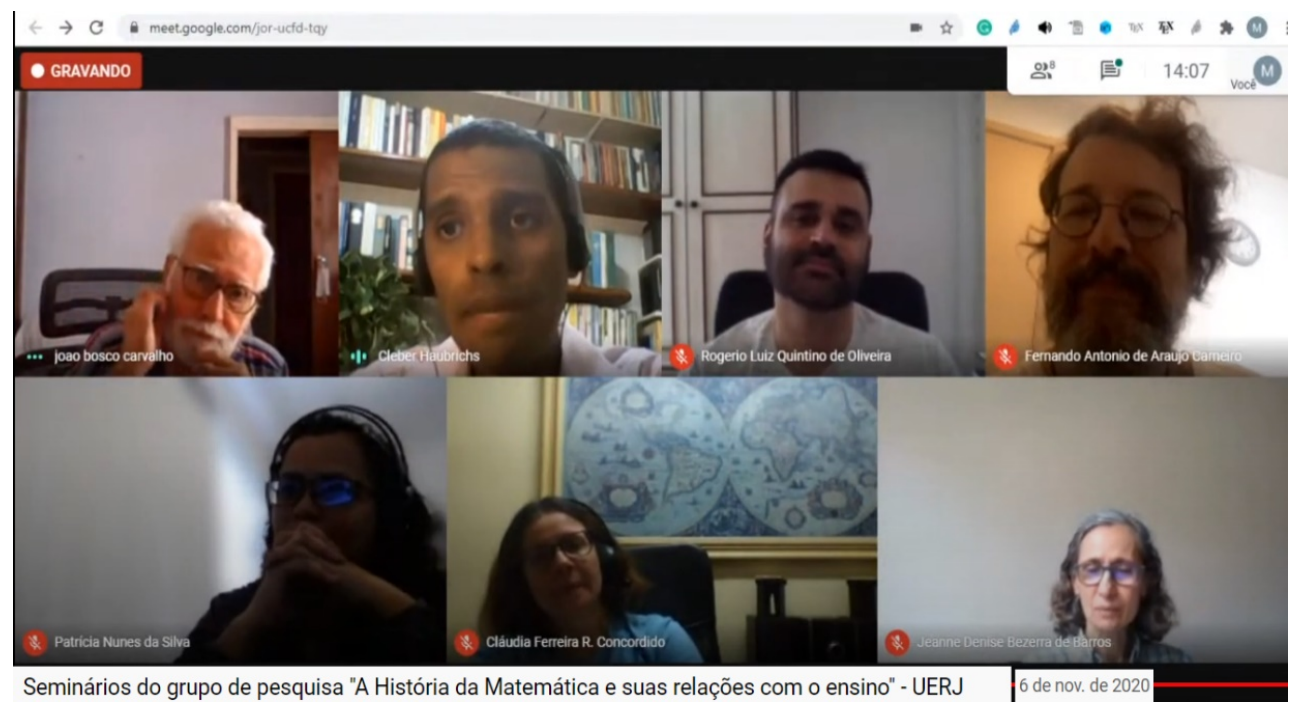

Vídeo disponível em: Seminário do grupo de pesquisa de história da Matemática

Rogerio não falava muito de sua vida pessoal, deixando transparecer uma certa melancolia em seu olhar nessas raras situações. Entre conversas percebi que era sensitivo (pessoas com a capacidade de perceber a presença de outras energias), mas não queria se aprofundar na sua busca espiritual como, por exemplo, sem se preocupar, por exemplo, com assuntos que tratam da existência da vida pós-morte. Muito menos se queixava das múltiplas atribulações que enfrentava na vida.

Finalizando o ano de 2020 tivemos diversas reuniões via online para decidir como seria o ENA (Exame Nacional de Acesso ao PROFMAT) e outros assuntos. Muitas horas de discussões foram necessárias e, por conta da pandemia, foi feita a opção pela prova online, assim como em outras universidades do país. Rogerio mostrava ser uma pessoa otimista e determinada.

É com muita tristeza que me despeço de meu amigo, e desse convívio amistoso tão breve!

Finalizo, aqui, com a frase do espiritualista brasileiro conhecido como Chico Xavier, que diz:

"Gostaria de dizer para você, que viva como quem sabe que vai morrer um dia, e que morra como quem soube viver direito."

Rosa Garcíd

\footnotetext{
${ }^{1}$ Rosa María García Márquez, professora associada na Faculdade de Formação de Professores, UERJ.
} 


\section{Depoimento da professora Angela Biazutti (UfRJ)}

Conheci o Rogerio em março de 2000, no primeiro dia de aula de Cálculo II, eu como professora e ele como aluno, sentado na primeira fileira de carteiras da sala de aula B-110, no prédio do centro de tecnologia, Ilha do Fundão. Começou sofrendo porque não faltou a primeira prova, mesmo estando doente com febre, e não foi bem na prova. A partir daí se sentiu obrigado a mostrar que era capaz de fazer melhor. E claro que fez muito melhor.

No período seguinte, como aluno de Cálculo III, já o tinha convidado para ser meu orientado de Iniciação Científica (IC). Sempre responsável, sempre entusiasmado em aprender coisas novas. Foi bolsista de IC por três anos e apresentou três trabalhos de IC em Jornadas de Iniciação Científica da UFRJ, "Séries de Potências, Autovalores e a Teoria Quântica de Estrutura Atômica", na XXIII JIC, em 2001; "Reatores Nucleares e Equações Diferenciais Parciais", na XXIV JIC, em 2002 e "Uma Aplicação do Teorema de Stone Weierstrass", na XXV JIC, em 2003.

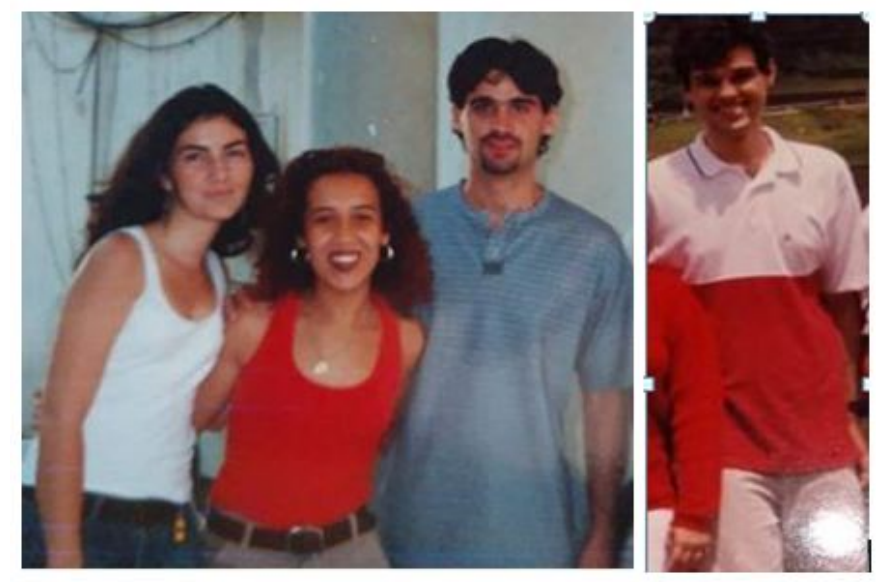

Os mosqueteiros: Cecília, Ana Carolina, Rogerio e André.

Naquela primeira fileira de carteiras também estavam os três amigos que completavam o grupo de mosqueteiros, junto com Rogerio: Cecília, Ana Carolina e André. Estudavam juntos, almoçavam juntos... Segundo Cecília, Rogerio era o mais engraçado, o mais divertido, com tiradas inteligentíssimas. Via tudo com muita clareza, e, por conta disso, sempre soube explicar muito bem. Era muito generoso com seu tempo. Chegava mais cedo em dias de prova para tirar dúvidas dos colegas.

"Cada vez que penso nele tenho que sorrir, lembrando dos momentos felizes que passamos juntos. Esta memória vai ficar comigo para sempre". (Cecília Salgado- professora da UFRJ) 
Após o término do curso de graduação, Rogerio foi aceito como aluno bolsista da CAPES, no mestrado em Matemática da UFRJ, onde tive de novo a satisfação de ser sua professora e orientadora da dissertação "Existência, Unicidade e Decaimento de Soluções de uma Equação de Onda com Dissipação Linear Localizada". Nesta época conheci a mãe de Rogerio, Elvira, certamente uma grande incentivadora do filho.

Mesmo já tendo optado por uma área específica, Equações Diferenciais Parciais, tinha interesse e curiosidade por outras áreas, tendo participado inclusive de congressos, como o de Geometria Diferencial, em São Paulo, no ano de 2004. Nesta viagem Rogerio estreitou amizade com Aline, também aluna do mestrado, só que na área de Geometria Diferencial. Ela conta que, quando passou no concurso para professora substituta da UFRJ, recebeu muito apoio e dicas sobre magistério de Rogerio, que já era professor substituto na UFRJ desde 2008. Um dava força para o outro durante o mestrado e o doutorado. Os dois foram aprovados em concursos para professor, ela na UFRRJ e ele na UERJ, em 2009, e concluíram doutorado em 2010.

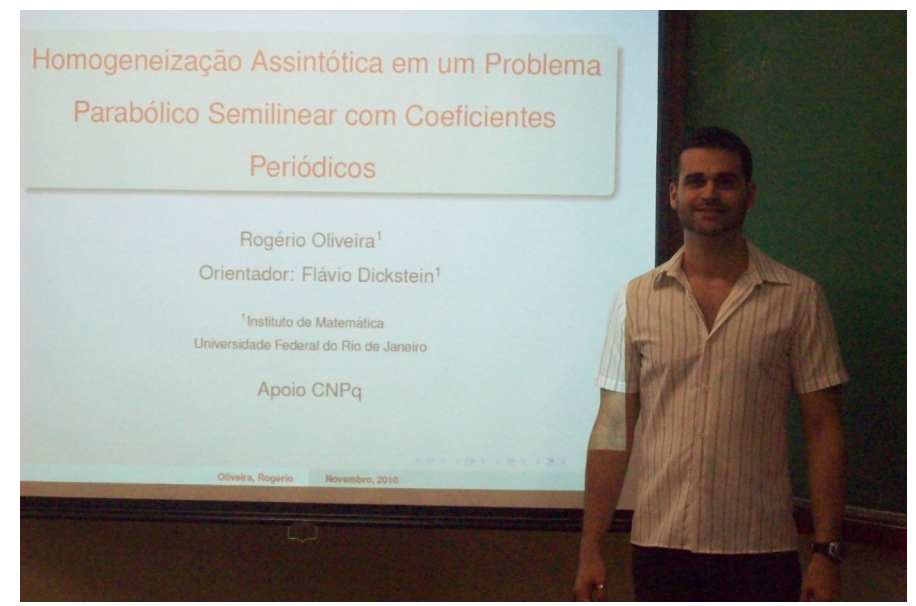

Defesa de Doutorado de Rogerio-2010.

Rogerio foi aluno bolsista do CNPq, do doutorado em Matemática da UFRJ, orientado pelo professor Flavio Dickstein, com a tese "Homogeneização Assintótica em um Problema Parabólico Semilinear com Coeficientes Periódicos". Aline continuou em contato com Rogerio, um convidava o outro para participar em bancas de seus alunos.

Segundo Aline, um gesto que ela nunca vai esquecer, foi a ajuda que Rogerio deu ao PROFMAT da UFRRJ, quando não foi permitida a aplicação de um exame de qualificação de um aluno lá, em virtude da pandemia da COVID-19, mas Rogerio se prontificou a aplicar a prova na UERJ. 


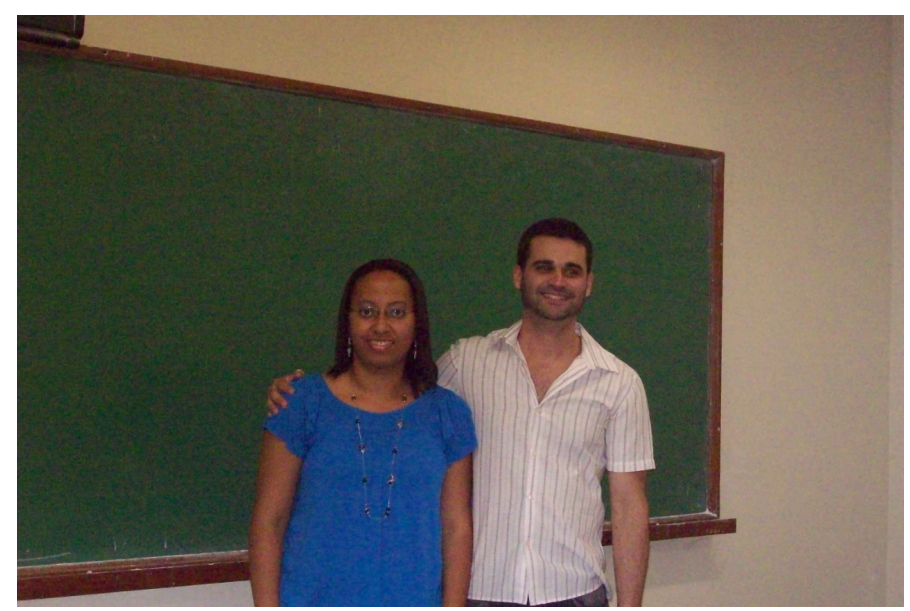

Rogerio e Aline Mauricio.

"O que fica hoje é gratidão e excelentes lembranças. Que Deus nos conforte e dê forças, principalmente à família de Rogerio". (Aline Mauricio, professora da UFRRJ)

Outra colega dos tempos de graduação, e amiga desde esta época, Ana Carolina, relata o último encontro presencial com Rogerio, em fevereiro de 2020, quando o convidou para sua primeira banca de mestrado. Conversaram muito, tomaram um café. Ela reforça o quanto ele era especial, com seu amor pelos amigos, responsável pelas pessoas de quem gostava, pelos alunos, perfeccionista em suas atividades. Segundo ela, era o melhor cérebro dos quatro mosqueteiros da época da graduação.

"Todos nós perdemos com a saída dele deste nosso plano. Ele passou por nós para deixar alguma coisa. E deixou. Cumpriu sua missão. Ainda vamos nos encontrar". (Ana Carolina Carius - professora do IFRJ-Caxias e da Universidade Católica de Petrópolis).

Meu último contato presencial com Rogerio foi em dezembro de 2019, quando ele participou da banca de um aluno meu do mestrado PROFMAT, na UFRJ. Depois disso, só uma banca do PROFMAT online, já durante a pandemia, em setembro de 2020. Rogerio sempre alegre, trazendo arquivo com suas observações para ser entregue ao aluno, com comentários importantes e pertinentes. Um educador durante toda a sua vida acadêmica, e esta é a herança que ele deixa para todos que foram seus alunos. 


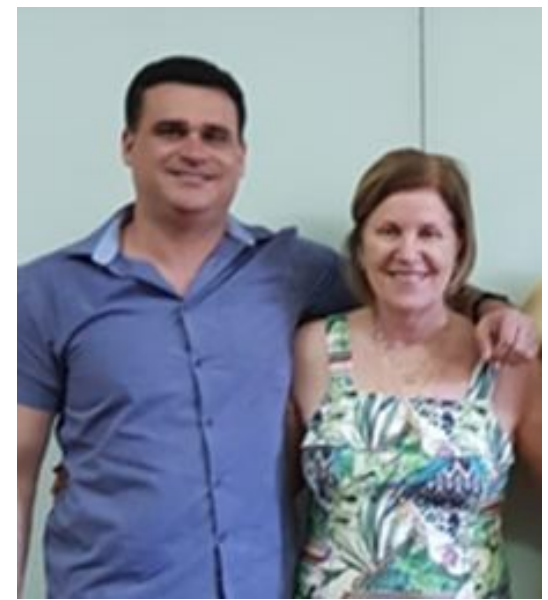

Rogerio e Angela - Dezembro de 2019

Foi um grande prazer tê-lo como aluno, como colega, como amigo. De todos os alunos quase-filhos que tive nestes 42 anos como professora, ele foi o que me trouxe mais orgulho (quem sabe um pouco pretensiosamente) de ter sido um pouquinho que seja responsável pelas suas vitórias e sucessos na profissão que escolheu. Ou que o escolheu.

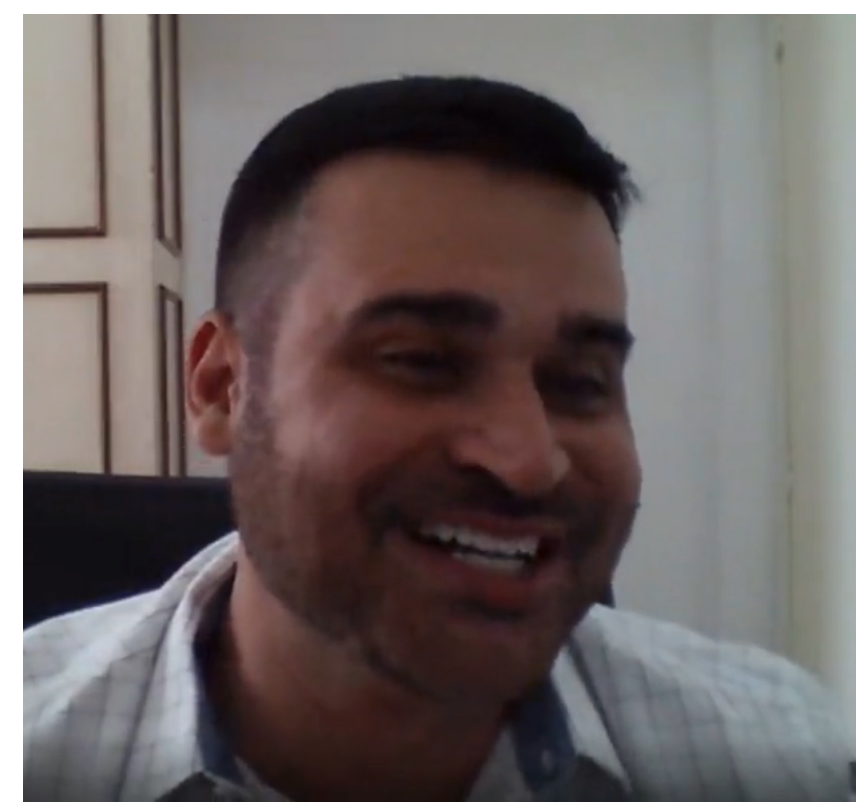

Angela Biazutt2

\footnotetext{
${ }^{2}$ Angela Cássia Biazutti, professora associada no Instituto de Matemática, UFRJ.
} 


\section{Homenagem ao professor Rogério - Daniel Lima}

Correto, disciplinado, objetivo e simples. Assim podemos definir o professor Rogério. O conheci na minha primeira aula do PROFMAT, em 2018, na disciplina Números e Funções. Ele tornou tudo tão simples. Sua objetividade e transparência fazia a aula ser leve e nem percebíamos ela passar.

Como sempre fui um aluno de sentar no fundo da sala, não era de conversar muito com os colegas e com ele. Com o tempo, ele percebeu que ficava meio isolado da turma e vinha até minha mesa e também na dos outros colegas perguntar se estava tudo bem e tirar dúvidas.

Sempre muito solicito.

Em 2019, tivemos o momento da escolha do orientador. Quando soube das suas propostas de pesquisa, fiquei muito animado e pedi que me orientasse. Ele aceitou e começamos a produção da dissertação. Passei por muitos problemas e ele sempre tentava me animar e me incentivar a não desistir. Por muitas vezes nossos encontros virtuais viraram sessões de terapia.

Sua partida foi um choque. Confesso que ainda me pergunto se você realmente se foi.

Como eu aprendi com você professor Rogério!

Agradeço as circunstâncias da vida por ter conhecido alguém tão humano e com uma compreensão ímpar.

Até logo!

Daniel Limd $3^{3}$

\footnotetext{
${ }^{3}$ Daniel Carvalho de Almeida Lima, orientando do Rogério no Mestrado Profissional em Matemática em Rede Nacional (PROFMAT), IME, UERJ.
} 